\title{
Artigo/Article
}

\section{Caracterização de cepas de referência de Leptospira sp utilizando a técnica de pulsed field gel electrophoresis}

\author{
Characterization of Leptospira sp reference strains using the pulsed field gel electrophoresis \\ technique
}

Lívia Machry ${ }^{1}$, Rachel Leite Ribeiro ${ }^{1}$, Juliana Magalhães Vital-Brazil ${ }^{1}$, Ilana Teruszkin Balassiano ${ }^{1}$, Ivi Cristina Menezes de Oliveira ${ }^{2}$, Kátia Eliane Santos Avelar ${ }^{2}$ e Martha Maria Pereira ${ }^{1}$

\begin{abstract}
RESUMO
Introdução: A leptospirose é uma zoonose endêmica, mundialmente distribuída, causada por bactérias do gênero Leptospira. Este gênero compreende espécies patogênicas e saprofíticas, com mais de 200 sorovares distintos, dificultando sua caracterização. A técnica de pulsed field gel electrophoresis tem sido empregada como uma ferramenta para auxiliar nesta caracterização. Os objetivos deste trabalho foram padronizar a técnica de PFGE, determinar os perfis moleculares das cepas de referência utilizadas pelo Laboratório de Referência Nacional para Leptospirose/Centro Colaborador da Organização Mundial de Saúde para Leptospirose e criar um banco de dados com estes perfis. Métodos: Foram analisadas, por PFGE, dezenove cepas utilizando a enzima de restrição NotI. Resultados: Cada cepa apresentou um perfil único que pode ser considerado como uma identidade genômica específica, com exceção dos sorovares Icterohaemorrhagiae e Copenhageni, cujos perfis foram indistinguíveis. Conclusões: Dessa forma, foi possível a criação de um banco de perfis moleculares que está sendo utilizado no Laboratório para a comparação e identificação de cepas isoladas de quadros clínicos.
\end{abstract}

Palavras-chaves: Leptospira sp. Pulsed Field Gel Electrophoresis. Leptospirose. Biologia molecular.

\begin{abstract}
Introduction: Leptospirosis is an endemic zoonosis of worldwide distribution, caused by bacteria of the genus Leptospira. This genus includes pathogenic and saprophytic species, with more than 200 different serovars, thus making it difficult to characterize. The technique of pulsed field gel electrophoresis has been used as a tool to aid in this characterization. The aims of this study were to standardize the PFGE technique, determine the molecular profiles of reference strains used at the National Reference Laboratory for Leptospirosis/World Health Organization Collaborating Center for Leptospirosis and create a database with these profiles. Methods: Nineteen strains were analyzed by means of PFGE, using the restriction enzyme NotI. Results: Each strain presented a unique profile that could be considered to be a specific genomic identity, with the exception of the serovars Icterohaemorrhagiae and Copenhageni, whose profiles were indistinguishable. Conclusions: It was possible to create a database of molecular profiles, which are being used in the Laboratory for comparing and identifying strains isolated from clinical cases.
\end{abstract}

Key-words: Leptospira sp. Pulsed Field Gel Electrophoresis. Leptospirosis. Molecular biology.

1. Laboratório de Referência Nacional para Leptospirose, Centro Colaborador da Organização Mundial da Saúde, Fundação Oswaldo Cruz, Rio de Janeiro, RJ. 2. Instituto de Microbiologia Professor Paulo de Góes, Universidade Federal do Rio de Janeiro, Rio de Janeiro, RJ.

Endereço para correspondência: Dra Lívia Machry. Laboratório de Referência Nacional para Leptospirose/ FIOCRUZ. Av. Brasil 4365, Pavilhão Rocha Lima/3o andar/sala 302, Manguinhos, 21040-900 Rio de Janeiro, RJ.

Telefax: 5521 2270-6565

e-mail: liviamachry@gmail.com

Recebido para publicação em 22/07/2009

Aceito em 09/02/2010

\section{INTRODUÇÃO}

A leptospirose é uma zoonose endêmica, mundialmente distribuída, causada por bactérias do gênero Leptospira. Este gênero compreende espécies patogênicas e saprofíticas, com mais de 200 sorovares distintos, dificultando sua caracterização. $\mathrm{O}$ agente etiológico da leptospirose pertence à ordem Spirochaetales, família Leptospiracea, gênero Leptospira ${ }^{1}$, caracterizado por bactérias de forma espiral longa, finas e flexíveis, com uma ou ambas as extremidades curvadas em forma de gancho. São aeróbias obrigatórias, que apresentam crescimento fastidioso in vitro nos meios de Fletcher ou Ellinghausen-McCullough-Johnson-Harris (EMJH), com pH de 6,8-7,4 e temperatura entre 28 e $30^{\circ} \mathrm{C}^{2-4}$. O isolamento e classificação de cepas patogênicas de leptospira são processos demorados, decorrentes principalmente da baixa taxa de crescimento, muitas vezes aliado à contaminação concomitante com microrganismos de crescimento mais rápido, e rigorosas exigências da cultura in vitro desta bactéria ${ }^{5}$.

Atualmente, as leptospiras podem ser classificadas tanto por métodos fenotípicos (convencionais) quanto por genotípicos. No sistema convencional, todas as leptospiras patogênicas pertencem à espécie Leptopira interrogans sensu lato ${ }^{5}$. Este sistema é baseado em critérios sorológicos nos quais as cepas de leptospiras são diferenciadas em sorovares. $\mathrm{O}$ sorovar é a unidade taxonômica básica utilizada para a classificação de leptospiras ${ }^{6}$. Porém, a identificação desse gênero bacteriano é bastante dificultada quando se observa que sorovares pertencentes ao mesmo sorogrupo encontram-se distribuídos entre diferentes espécies ${ }^{2,4,6,7}$.

A sorotipagem é determinada pelo teste de aglutinação microscópica com absorção cruzada (cross-aglutinin absorption test - CAAT), no qual são utilizados soros imunes de referência produzidos em coelhos ${ }^{8}$. O CAAT é demorado e restrito a 
laboratórios de referência internacional, pois requer a existência de uma coleção completa de cepas de referência do gênero Leptospira; entretanto, é essencial na identificação de novos sorovares ${ }^{9,10}$. Outro método é o teste de microaglutinação MAT (microscopic agglutination test) usando anticorpos monoclonais específicos ${ }^{8,10}$ que, mesmo quando apresenta títulos elevados para um determinado sorovar, embora sugestivo, não é conclusivo a respeito do sorovar infectante, devido à ocorrência de reações cruzadas ${ }^{11}$. A identificação dos sorovares é importante para a epidemiologia, uma vez que eles apresentam relações diretas com alguns animais reservatórios, focos de infecção e distribuição geográfica ${ }^{3}$.

Mais recentemente, o sistema genotípico tem agrupado as leptospiras em 20 espécies, definidas com base na hibridização DNA$\mathrm{DNA}^{6}$. Além desta, outras técnicas de biologia molecular têm sido aplicadas para a classificação genética e identificação de sorovares de leptospira, entre elas: hibridização DNA-rRNA, restriction endonuclease analysis (REA), randomly amplified polymorphic DNA Fingerprint (RAPD), arbitrarily primed PCR (AP-PCR) ${ }^{10}$. Dentre as metodologias de tipagem molecular, a técnica de pulsed field gel electrophoresis (PFGE) é uma ferramenta epidemiológica considerada padrão ouro ${ }^{8,12-15}$, pois permite comparar cepas bacterianas isoladas de um mesmo surto e de surtos ocorridos em diferentes regiões geográficas $^{16}$.

A diversidade apresentada pelos vários sorovares demonstra a necessidade de uma correta identificação destas amostras, uma vez que os microrganismos do gênero Leptospira apresentam importante participação no cenário de infecções humanas e animais. Diante disso, o objetivo deste trabalho foi padronizar a técnica de PFGE para Leptospira sp no Laboratório de Referência Nacional para Leptospirose (LRNL)/Centro Colaborador da Organização Mundial de Saúde para Leptospirose (CC/OMS); a fim de caracterizar genotipicamente as cepas de referência utilizadas para a realização do diagnóstico sorológico pela técnica de MAT, iniciando a criação de um banco de perfis genômicos para auxiliar na futura identificação de isolados clínicos.

\section{MÉTODOS}

Foram analisadas dezenove cepas de Leptospira sp que compõem o painel de antígenos de referência recomendado pela Organização Mundial de Saúde (OMS) para o diagnóstico sorológico da leptospirose, pela técnica de $\mathrm{MAT}^{10}$. As cepas (Figura 1) foram originalmente fornecidas pelo Centro de Referência Mundial da OMS/FAO/OIE e Centro de Referência Nacional do Instituto de Medicina Tropical da Holanda, e correspondem a uma fração da Coleção de Culturas do LRNL-CC/OMS, localizado no Instituto Oswaldo Cruz (Fundação Oswaldo Cruz), Rio de Janeiro, Brasil.

O protocolo padronizado pelo grupo teve como base as metodologias descritas por Taylor e cols ${ }^{17} \mathrm{e}$ Naigowit cols ${ }^{18}$ resultando em um prazo de cinco dias para a execução da técnica ${ }^{19}$.

Os moldes de DNA bacteriano, a serem analisados, foram preparados a partir de $10 \mathrm{ml}$ de culturas de Leptospira em meio líquido EMJH (DIFCO). A cultura foi centrifugada por 20 minutos a $16.000 \mathrm{X} g$ numa temperatura entre 4 e $8^{\circ} \mathrm{C}$ e o sedimento foi ressuspenso em solução salina estéril a fim de medir sua densidade óptica (DO), em espectrofotômetro (650nm), sendo definida a DO de Leptospira entre 0,25 e $0,35 \mathrm{~nm}$, como a ideal para a realização do PFGE. A suspensão foi centrifugada por 2 minutos a $16.000 \mathrm{X}$ g e o sedimento foi ressuspenso em tampão PIV (Tris $\mathrm{HCl}$ 0,01M;

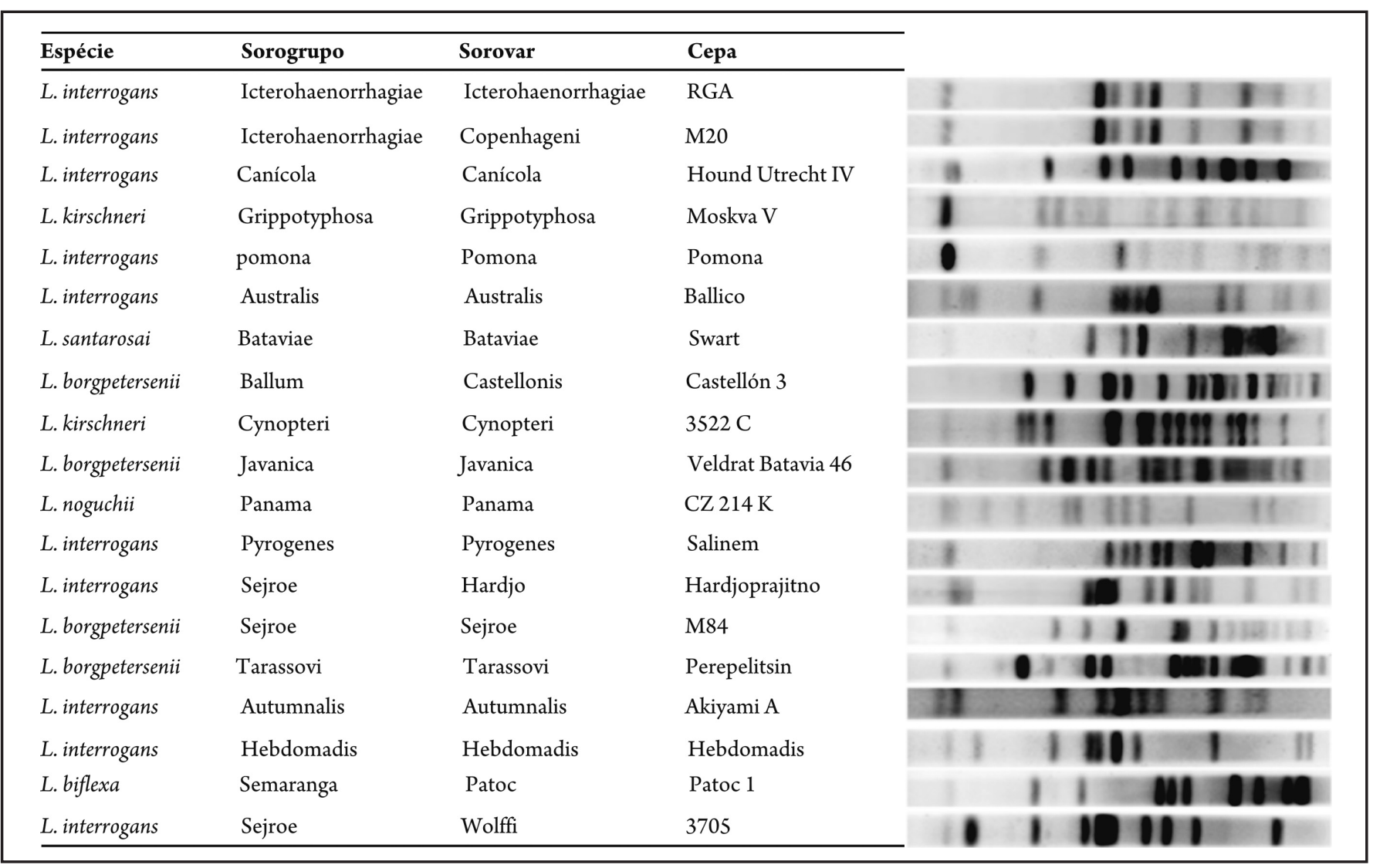

FIGURA 1 - Perfil dos sorovares de Leptospira spp com enzima de restrição NotI. 
$\mathrm{NaCl} 1 \mathrm{M}$ ) adicionado de um igual volume de agarose de baixo ponto de fusão a 1,5\% (agarose low melting point, SIGMA) para preparação dos moldes.

Depois de solidificados $\left( \pm 4^{\circ} \mathrm{C}\right.$ por $\left.15 \mathrm{~min}\right)$, os moldes foram incubados em solução tampão EC (Tris $\mathrm{HCl} 1 \mathrm{M} ; \mathrm{NaCl} 2 \mathrm{M}$; EDTA tetrassódico $1 \mathrm{M}$; desoxicolato de sódio $2 \%$; sarcosil $5 \%$ ) com lisozima $(1 \mathrm{mg} / \mathrm{ml})$ e RNAse A $(10 \mu \mathrm{g} / \mathrm{ml})$ a $37^{\circ} \mathrm{C}$ por 18 horas, a fim de lisar as células bacterianas. As proteínas liberadas com a lise celular foram removidas pela incubação com solução tampão ES (EDTA tetrassódico $1 \mathrm{M}, \mathrm{pH} 8,0$; sarcosil $5 \%)$ contendo proteinase $\mathrm{K}(1 \mathrm{mg} / \mathrm{ml})$ a $51^{\circ} \mathrm{C}$ por 24 horas. Antes da digestão com a enzima de restrição, os moldes de agarose foram submetidos a 8 lavagens com tampão TE (Tris $\mathrm{HCl} 1 \mathrm{M}$; EDTA dissódico 0,5M) pH 7,5 em temperatura ambiente, por 1 hora cada uma, seguido de incubação com $25 \mathrm{U}$ da enzima de restrição NotI, segundo recomendações do fabricante. A separação dos fragmentos de DNA do cromossoma bacteriano clivado pela enzima de restrição foi feita através do sistema de CHEF-DR III (Bio-Rad Laboratories, USA) em gel de agarose a 1,3\% através de uma corrida de 22 horas com tempos de pulso inicial de 5,5 segundos e final de 63,5 segundos, voltagem de $6 \mathrm{Vcm}^{-1} \mathrm{com}$ recirculação de tampão TBE $0,5 \mathrm{X}$ (Tris $\mathrm{HCl}$ 0,89M; ácido bórico 0,89M; EDTA dissódico 0,5M) contendo $100 \mu \mathrm{mol} / \mathrm{L}$ de tiuréia a temperatura de $14^{\circ} \mathrm{C}$ e ângulo fixo de $120^{\circ}$. Foi utilizado o marcador de tamanho molecular como padrão Pulse Marker 0,5-1.000 Kb (SIGMA).

O gel foi corado com solução de brometo de etídio a $0,5 \mathrm{mg} / \mathrm{mL}$ por 60 minutos, descorado em água por 120 minutos e, em seguida, observado em transiluminador de UV e fotografado.

A análise do polimorfismo genético das cepas de Leptospira sp foi realizada visualmente a partir dos padrões de bandas produzidos por PFGE, após digestão do DNA com a endonuclease de restrição NotI, seguindo os critérios de Tenover cols ${ }^{16}$.

\section{RESULTADOS}

A Figura 1 mostra os géis representativos dos perfis de PFGE obtidos, com a respectiva identificação das cepas em nível de espécie, sorogrupo e sorovar. Todos os sorovares apresentaram perfis únicos e característicos, com diferentes quantidades de fragmentos de restrição ( 8 a 16) e tamanhos moleculares dos mesmos (50$1.000 \mathrm{~Kb}$ ); exceto os sorovares Icterohaemorrhagiae e Copenhageni, cujos perfis apresentam-se idênticos com o mesmo número e tamanho de bandas.

\section{DISCUSSÃO}

O método de PFGE foi padronizado no LRNL-CC/OMS para a caracterização do painel de antígenos de leptospira usado como referência para o exame sorológico de microaglutinação (MAT), considerado padrão-ouro para o diagnóstico da leptospirose. $\mathrm{O}$ painel é formado pelas cepas de referência dos sorovares mais representativos do ponto de vista clínico e, por isso, é distribuído pelo LRNL-CC/OMS para a rede nacional de Laboratórios Centrais (LACENs) que realizam o diagnóstico da leptospirose.

A escolha do PFGE como técnica de identificação de leptospiras ${ }^{15}$ leva em consideração que, para que possam ser feitos estudos epidemiológicos da leptospirose, faz-se necessária a classificação fenotípica dessas bactérias isoladas. Uma técnica opcional seria a realização do CAAT; contudo, como referenciado por alguns autores $^{2-4,15}$, a mesma é considerada laboriosa. A identificação de sorovares desconhecidos consome tempo, o que pode levar em torno de até dois meses. Tempo extremamente prolongado para responder as questões epidemiológicas relacionadas a surtos ${ }^{13}$. Já a utilização do método de PFGE oferece como vantagens o fornecimento de uma resposta relativamente rápida (em torno de uma semana) para identificação de sorovares, além de ser de fácil interpretação ${ }^{20}$.

O protocolo padronizado por nosso grupo resultou em um prazo de cinco dias para a execução da técnica. Galloway \& Levett ${ }^{12}$ propuseram uma alternativa que visava minimizar o tempo de desenvolvimento do PFGE, acrescentando SDS (dodecil sulfato de sódio) e proteinase $\mathrm{K}$ no próprio molde de agarose. O protocolo resultou em uma considerável economia de tempo total na execução da técnica de cinco para dois dias. No entanto, quando testada no nosso laboratório, esta metodologia não se mostrou satisfatória por não resultar em uma boa resolução, provavelmente devido à degradação do DNA. Para superar este tipo de dificuldade, no nosso protocolo, o tampão de corrida foi acrescido de $100 \mu \mathrm{mol} / \mathrm{L}$ de tiuréia, resultando na minimização da degradação do DNA e consequente melhoria na resolução do gel, facilitando a visualização das bandas ${ }^{19}$.

Taylor cols ${ }^{17}$ utilizaram o PFGE para estudar o genoma de espécies de Leptospira, caracterizando o tamanho e estrutura do genoma de Leptospira interrogans e Leptospira biflexa (espécies, respectivamente, patogênica e saprofítica) e, utilizando um total de dez diferentes enzimas de restrição, entre elas NotI, SmaI, ApaI e SacП, observaram diferenças na migração dos fragmentos de DNA digerido entre as duas espécies. Outro estudo utilizando diferentes enzimas de restrição (NotI e SgrAI) compara as técnicas de MAT e PFGE para identificação de 72 sorovares de referência de leptospiras do National Reference Center Collection (Paris, França) e mostra que a enzima NotI permitiu a identificação de 64 sorovares, sendo os demais diferenciados pela enzima $\operatorname{SgrAI}{ }^{13}$.

Em nosso estudo, na busca pelo perfil molecular ideal de análise, também empregamos diferentes enzimas de restrição, algumas utilizadas em publicações anteriores e outras não relatadas, dentre as quais: NotI, SmaI, HaeIII, HindIII, SpeI, EcoRI, BglII. Observamos que as enzimas empregadas reconhecem inúmeros sítios de restrição no genoma da leptospira, resultado ocasionalmente em perfis genéticos indistinguíveis (dados não mostrados). Já a enzima NotI clivou o DNA das cepas de referência gerando fragmentos com padrões de migração distintos e perfis que podem ser padronizados para as dezenove cepas de referência utilizadas. A escolha desta enzima para a caracterização das cepas tem como base os resultados concordantes entre o perfil obtido com a utilização da enzima e a análise com anticorpos monoclonais ${ }^{12,18,20}$. Constatamos, com nossos resultados, que todos os sorovares apresentaram padrões únicos e distinguíveis entre si, exceto os sorovares Icterohaemorrhagiae e Copenhageni. Os mesmos mostraram perfis idênticos com o uso da enzima NotI, o que impossibilitou sua diferenciação. É importante mencionar que a semelhança entre esses dois sorovares se expressa também na sorologia pelo MAT, utilizandose anticorpos policlonais, onde se observa reação cruzada com títulos da mesma magnitude ${ }^{8,12}$. Romero cols ${ }^{15}$ também falharam na diferenciação destes sorovares empregando esta mesma enzima.

A padronização de um banco de perfis genômicos abrangendo as cepas de referência de leptospira mostra-se como uma ferramenta potencialmente aplicável à identificação, por meio de comparação, de cepas clínicas patogênicas recebidas e/ou isoladas pelo LRNLCC/OMS. 


\section{AGRADECIMENTOS}

Os autores agradecem a Tatiane Mendes Varela Ramos pelo apoio técnico.

\section{CONFLITO DE INTERESSE}

Os autores declaram não haver nenhum tipo de conflito de interesse no desenvolvimento do estudo.

\section{SUPORTE FINANCEIRO}

Secretaria de Vigilância em Saúde, Ministério da Saúde, Instituto Oswaldo Cruz da Fundação Oswaldo Cruz.

\section{REFERÊNCIAS}

1. Paster BJ, Dewhirst FE, Weisburg WG, Tordoff LA, Fraser GJ, Hespell RB, et al. Phylogenetic Analysis of the Spirochetes. J Bacteriology 1991; 173: 61016109.

2. Adler B, Moctezuma AP. Leptospira and leptospirosis. Vet Microbiology 2010; 140:287-296.

3. Bharti AR, Nally JE, Ricaldi JN, Matthias MA, Diaz MM, Lovett MA, et al. Leptospirosis: a zoonotic disease of global importance. Infect Diseases 2003; 3 : $757-771$.

4. Levett PN. Leptospirosis. Clin Microbiol Reviews 2001; 14: 296-326.

5. Valverde ML, Ramírez JM, Montes de Oca LG, Goris MG, Ahmed N, Hartskeerl RA. Arenal, a new Leptospira serovar of serogroup Javanica, isolated from a patient in Costa Rica. Infection, Genetics and Evolution 2008; 8: 529-533.

6. Cerqueira GM, Picardeau M. A century of Leptospira strain typing. Infection, Genetics and Evolution 2009; 9: 760-768.

7. Vijayachari P, Sugunan AP, Shriram AN. Leptospirosis: an emerging global public health problem. J Biosciences 2008; 33: 557-569.

8. Herrmann JL, Baril C, Bellenger E, Perolat P, Baranton G, Saint Girons I. Genome Conservation in Isolates of Leptospira interrogans. J Bacteriology 1991; 173: $7582-7588$

9. Romero EC, Yasuda PH. Molecular characterization of Leptospira sp strains isolated from human subjects in São Paulo, Brazil using a polymerase chain reaction-based assay: a public health tool. Mem Inst Oswaldo Cruz 2006; 101: 373-378.

10. World Health Organization. Human leptospirosis: guidance for diagnosis, surveillance and control. World Health Organization, Geneva, Switzerland, 2003.

11. Ahmad SN, Shah S, Ahmad FM. Laboratory diagnosis of leptospirosis. J Postgraduate Medicine 2005; 51: 195-200.

12. Galloway RL, Levett PN. Evaluation of a Modified Pulsed-Field Gel Electrophoresis Approach for the Identification of Leptospira Serovars. Am J Trop Med and Hygiene 2008; 78: 628-632.

13. Herrmann JL, Bellenger E, Perolat P, Baranton G, Saint Girons I. Pulsed-Field Gel Electrophoresis of NotI Digests of Leptospiral DNA: a New Rapid Method of Serovar Identification. J Clin Microbiol 1992; 30: 1696-1702.

14. Olive DM, Bean P. Principles and Applications of Methods for DNA-Based Typing of Microbial Organisms. J Clin Microbiol 1999; 37: 1661-1669.

15. Romero EC, Blanco RM, Galloway RL. Application of pulsed field gel electrophoresis for the discrimination of leptospiral isolates in Brazil. Letters in Appl Microbiol 2009; 48: 623-627.

16. Tenover FC, Arbeit RD, Goering RV, Mickelsen PA, Murray BE, Persing DH, et al. Interpreting Chromosomal DNA Restriction Patterns Produced by PulsedField Gel Electrophoresis: Criteria for Bacterial Strain Typing. J Clin Microbiol 1995; 33: 2233-2239.
17. Taylor KA, Barbour AG, Thomas DD. Pulsed-Field Gel Electrophoresis Analysis of Leptospiral DNA. Infec and Immunity 1991; 59: 323-329.

18. Naigowit P, Charoenchai S, Biaklang M, Seena U, Wangroongsarb P, Sawanpanyalert $\mathrm{P}$, et al. Identification of Clinical Isolates of Leptospira spp by Pulsed-Field Gel Electrophoresis and Microscopic Agglutination Test. Southeast Asian J Trop Medicine and Public Health 2007; 38: 97-103.

19. Ribeiro RL, Machry L, Brazil JMV, Ramos TMV, Avelar KES, Pereira MM Technical improvement to prevent DNA degradation of Leptospira spp in pulsed field gel electrophoresis. Letters in Applied Microbiol 2009; 49: 289-291.

20. Ciceroni L, Ciarrocchi S, Ciervo A, Petrucca A, Pinto A, Calderaro A, et al Differentiation of leptospires of the serogroup Pomona by monoclonal antibodies, pulsed-field gel electrophoresis and arbitrarily primed polymerase chain reaction. Res Microbiol 2002; 153: 37-44. 